\title{
Targeting the Mucosal Barrier: How Pathogens Modulate the Cellular Polarity Network
}

\author{
Travis R. Ruch ${ }^{1}$ and Joanne N. Engel ${ }^{1,2}$ \\ ${ }^{1}$ Department of Medicine, University of California, San Francisco, San Francisco, California 94143 \\ ${ }^{2}$ Department of Microbiology and Immunology, University of California, San Francisco, San Francisco, \\ California 94143 \\ Correspondence: jengel@medicine.ucsf.edu
}

\begin{abstract}
The mucosal barrier is composed of polarized epithelial cells with distinct apical and basolateral surfaces separated by tight junctions and serves as both a physical and immunological barrier to incoming pathogens. Specialized polarity proteins are critical for establishment and maintenance of polarity. Many human pathogens have evolved virulence mechanisms that target the polarity network to enhance binding, create replication niches, move through the barrier by transcytosis, or bypass the barrier by disrupting cell-cell junctions. This review summarizes recent advances and compares and contrasts how three important human pathogens that colonize mucosal surfaces, Pseudomonas aeruginosa, Helicobacter pylori, and Neisseria meningitidis, subvert the host cell polarization machinery during infection.
\end{abstract}

$T^{\mathrm{h}}$ he mucosal barrier is composed of one or more layers of epithelial cells that have distinct apical and basolateral surfaces with specialized functions. These cells form a selective permeability barrier between biological compartments that serves as both a physical and immunological barrier to invading microbes (Wang and Margolis 2007; Martin-Belmonte and Mostov 2008). However, pathogens circumvent this barrier using a diverse array of strategies including transcytosis through epithelial cells, disrupting cell-cell contacts, or killing epithelial cells. In this review, we discuss three pathogens that specifically target the polarity signaling network and discuss the mechanisms they use.

The apical and basolateral membrane domains are distinguished by unique assemblies of proteins and lipids, creating specific membrane domains with distinct roles in formation and maintenance of barrier function. The apical surface contains transporters and enzymes that are specialized to interact with the external environment. The basolateral plasma membrane is enriched in phosphatidylinositol 3,4,5-phosphate and contains many transporters and receptors that are involved in nutrient uptake from the blood (Shewan et al. 2011). Tight junctions sit just below the apical membrane on the lateral surface. They have a "gate" function that regulates paracellular transit of molecules and a "fence" function that regulates movement within the cell membrane. Several transmembrane proteins are localized to tight junctions, including claudins occludin, tricellulin, marvel, and junctional adhesion molecules (JAMs), that

Editor: Keith E. Mostov

Additional Perspectives on Cell Polarity available at www.cshperspectives.org

Copyright (C) 2017 Cold Spring Harbor Laboratory Press; all rights reserved; doi: 10.1101/cshperspect.a027953

Cite this article as Cold Spring Harb Perspect Biol 2017;9:a027953 
play roles in tight junction adhesion, permeability, and signaling (Anderson and Van Itallie 2009; Shen et al. 2011). Cytoplasmic proteins, like those of the zonula occludins family (ZO-1, $\mathrm{ZO}-2, \mathrm{ZO}-3)$, link the tight junction to the actin cytoskeleton. The adherens junction sits basal to the tight junction and physically connects neighboring cells to give the epithelial sheet mechanical resiliency. Cadherin, a type I singlepass transmembrane protein, forms homotypic bonds with cadherin molecules on neighboring cells in a calcium-dependent fashion. These cross-cell protein-protein connections generate the adhesive forces that hold epithelial cells together. The cadherin tail interacts with the cytoplasmic catenin proteins $(\beta$-catenin, $\alpha$-catenin, p120-catenin) to control adhesive function, connection to the actin cytoskeleton, cadherin internalization, and other signaling functions (Capaldo et al. 2014). Like cadherin, the transmembrane protein nectin forms intramolecular bridges between cells. However, the cytoplasmic tail of nectin binds to the cytoplasmic protein afadin, which connects nectin to the actin cytoskeleton (Ogita et al. 2010).

Three polarity complexes play crucial roles in the establishment and maintenance of polarity, the partitioning defective (PAR) complex, the Crumbs (CRB) complex, and the Scribble (SCR) complex. The identity of these complexes is based on genetic screens performed in Caenorhabditis elegans and Drosophila melanogaster in the context of several different types of cell polarization (Kemphues et al. 1988; Tepass et al. 1990; Tepass and Knust 1993; Tabuse et al. 1998; Bhat et al. 1999; Bilder et al. 2000; Bilder and Perrimon 2000). The Par complex is composed of three core protein components, Par3, Par6, and atypical protein kinase $\mathrm{C}$ (aPKC) (Kemphues et al. 1988; Tabuse et al. 1998). Par3 and Par6 are both scaffolding proteins, and aPKC is a kinase that phosphorylates a number of polarity proteins (McCaffrey and Macara 2009). The mammalian CRB complex has four core protein members: Crumbs (Crb), Pals1, Patj, and MUPP1. Crumbs is a transmembrane protein that localizes to the apical domain, whereas Pals1, PatJ, and MUPP1 are scaffolding proteins (Roh et al. 2002). The SCR complex consists of three scaffolding proteins, Scribbled (Scrb), Discs large (Dlg), and Lethal giant larvae $(\mathrm{Lgl})$ (Navarro et al. 2005; Su et al. 2012).

The PAR, CRB, and SCR complexes all play an important role in epithelial cell polarity; however, there are important differences in how the polarity complexes act in the context of mammalian cell polarity compared to other types of cell polarity operative during embryogenesis, cell division, or neuronal polarity. For example, in mammalian epithelial cells, the PAR unit does not form a stable complex. Rather, Par3 localizes to the tight junction, whereas aPKC and Par6, along with the Rho GTPase Cdc42, localize to the apical membrane (Bryant et al. 2010). In addition, the kinase Parl functions as part of the basolateral SCR complex (Goehring 2014). The CRB complex along with aPKC, Par6, and Cdc42 define the apical membrane, Par3 defines the apical junction, and the SCR complex along with Parl define the basolateral domain. A series of antagonistic signaling events maintains this asymmetric distribution by creating zones of mutual exclusion between the apical, junctional, and basolateral domains (Assemat et al. 2008). If Par3 moves into the apical space it can be phosphorylated by aPKC, disrupting its membrane localization (Morais-de-Sa et al. 2010; Walther and Pichaud 2010). In a similar fashion, if Par3 migrates into the basolateral space it is phosphorylated by Par1 and diffuses away (Benton and St Johnston 2003; Wang et al. 2012). In addition, aPKC/Par6 and Par1/Lgl are mutually inhibitory (RodriguezBoulan and Macara 2014). These negative interactions set up the basis for apical basolateral polarity (Fig. 1) (Goehring 2014). The presence of multiple paralogs and splice isoforms of the polarity proteins adds to the complexity of polarity signaling. For example, the human genome encodes two paralogs of Par3 each with multiple splice isoforms (ten for PARD $3 A$, and five for $P A R D 3 B$ ). The role of so many potential isoforms is not fully understood, but may allow for signaling plasticity that allows the network to regulate cell polarity in a wide range of cell types (Assemat et al. 2008; McCaffrey and Macara 2009; Apodaca et al. 


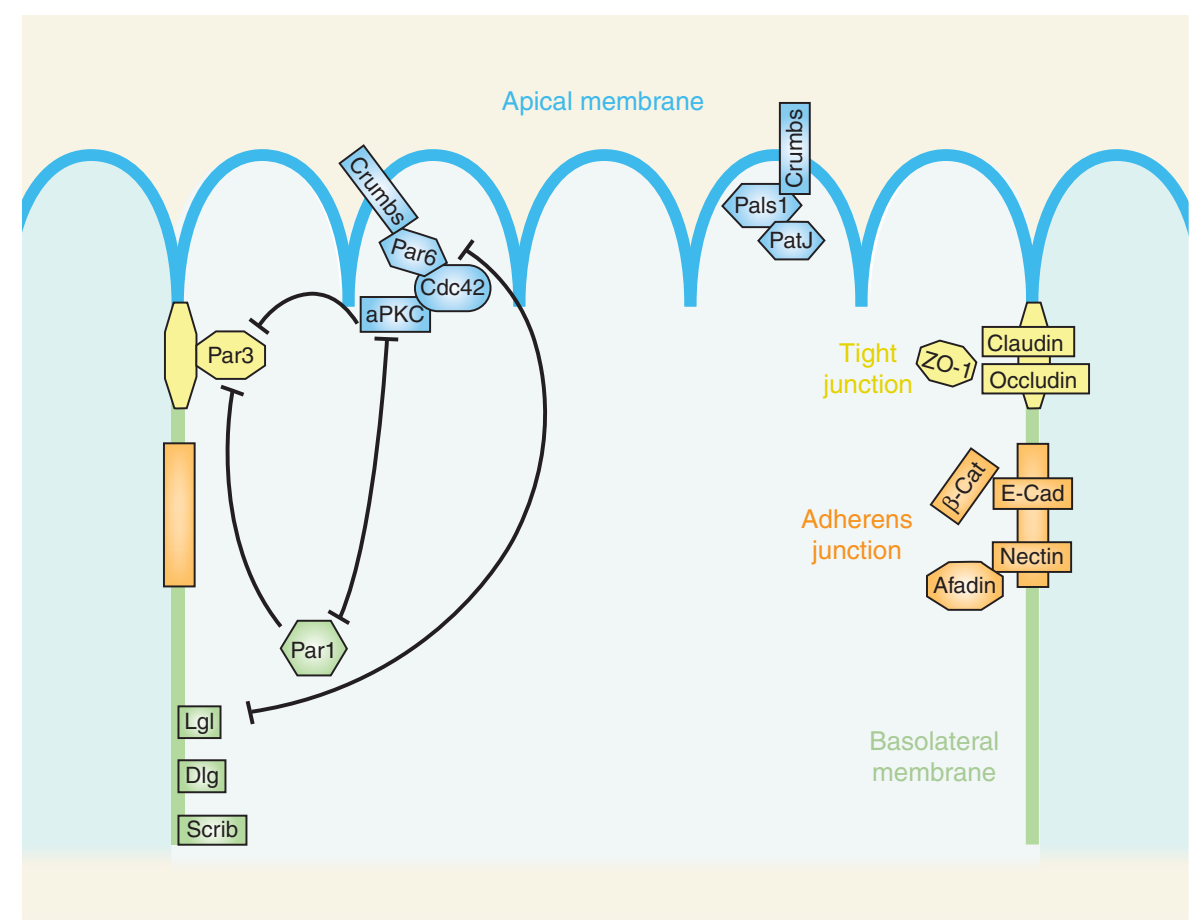

Figure 1. Antagonistic signaling events maintain epithelial cell polarity. The major inhibitory interactions between the apical, junctional, and basolateral domains are shown. Color coding shows apical domain (blue), basolateral domain (green), adherens junction (orange), and tight junction (yellow).

2012; Rodriguez-Boulan and Macara 2014; Flores-Benitez and Knust 2016).

Cell culture models have been critical for increasing our understanding how polarity signaling intersects with pathogens. To properly model the barrier, cell lines must be able to polarize in culture. Commonly used lines such as Madin-Darby canine kidney (MDCK), Calu-3 (human lung adenocarcinoma), 16HBE (human bronchial epithelial) Caco-2 (colorectal adenocarcinoma), and hCMEC/D3 (human brain endothelial cell) form highly polarized and impermeable monolayers with distinct apical and basolateral membrane domains when grown on porous filter supports. In contrast, growth of these cells on plastic surfaces does not fully allow recapitulation of mucosal barrier polarity. Furthermore, these simplified systems facilitate the study of pathogen-polarized cell interactions without the confounding effects of the underlying stroma or immune cells. In addition, microbes can be added directly to the apical and basolateral side of the cells without disrupting the monolayer allowing for the study of domain-specific responses to pathogens. This reductionist approach creates an experimental system to analyze host-pathogen interactions, which can then be translated into more complex cell culture models, including three-dimensional cultures, organoids, and animal models.

\section{Pseudomonas aeruginosa}

P. aeruginosa is a Gram-negative environmental bacterium that is a frequent and often fatal cause of opportunistic infections in humans. Its preference for injured tissue explains its ability to cause ventilator-associated pneumonia, skin and soft tissue infections in burn patients or at surgical incisions, and bacteremia in patients receiving cytotoxic chemotherapy. 
$P$. aeruginosa is also a cause of chronic lung infections and ultimately death in patients with cystic fibrosis (Bennett et al. 2015). Multidrug-resistant strains of $P$. aeruginosa are increasingly frequently seen in the clinical setting, and the Centers for Disease Control listed $P$. aeruginosa as a "serious" threat to public health.

Most $P$. aeruginosa infections, such as acute lung infections, are initiated by binding at the mucosal barrier through two major adhesins, flagella, and retractile type IV pili (Zanin et al. 2016). Once colonization is established, P. aeruginosa unleashes its virulence factors to cause disease. These include toxins directly injected into the host cell by the type III secretion system (TTSS), a needle like nanosyringe that is required for virulence in cell culture models, in animal models, and in human infections (Engel 2003; Hauser 2009). Polarized cell culture models have provided important insights into early events during infection that might have otherwise been missed when studying bacterial-host interactions in incompletely polarized cells. In polarized MDCK or human lung epithelial cells, $P$. aeruginosa binds to the apical surface at or near cell-cell junctions through its flagellum or its retractile type IV pili (Engel and Eran 2011). The binding of a few sentinel bacteria leads to recruitment of free swimming bacteria, with the resultant formation of an antibioticresistant biofilm-like bacterial aggregate composed of ten to hundreds of bacteria on the cell surface encased in a polysaccharide matrix (Lepanto et al. 2011; Tran et al. 2014b). Formation of the bacterial aggregate is associated with a dramatic remodeling of the apical membrane in MDCK cells within $30 \mathrm{~min}$ of infection. Initially, phosphatidylinositol 3-kinase (PI3K) is recruited to and activated underneath the aggregate, leading to the synthesis of the basolateral phosphoinositide $\mathrm{PIP}_{3}$ at the apical membrane (Kierbel et al. 2005). Generation of apical $\mathrm{PIP}_{3}$ then leads to activation of the kinase Akt and remodeling of the apical actin network into a protrusion through Rac1-mediated signaling (Kierbel et al. 2007; Tran et al. 2014a). The protrusion acquires basolateral proteins (such as p58) through a dynamin-specific pathway and loses apical markers (such as podocalyxin), consistent with an inversion of membrane polarity underneath bacterial aggregates (Kierbel et al. 2007). Tight junction components, such as ZO-1 and occludin, are not recruited to the protrusion, and tight junction function is not disrupted during protrusion formation. However, adherens junction components accumulate, including E-cadherin, Nectin-1, and $\beta$-catenin, suggesting that the protrusion may resemble a nascent adherens junction (Kierbel et al. 2007; Tran et al. 2014a). In addition, the PAR complex (Par3/Par6/aPKC) is recruited to the apical membrane underneath aggregates and is required for polarity inversion (Fig. 2) (Tran et al. 2014a). Because both aPKC and Par6 are found at the apical membrane in polarized cells, relocalization of Par3 from the tight junction to the apical membrane may be the driver of polarity disruption. Indeed, forced apical relocalization of Par3 is sufficient to recapitulate apical membrane remodeling, with cell polarity inversion and formation of an apical bulge (TR Ruch et al., in prep.). At later time points postinfection $P$. aeruginosa is able to bypass the epithelial barrier in other ways, such as killing cells or causing a redistribution of junctional proteins using its repertoire of T3SS toxins (Soong et al. 2008; Hauser 2009).

Formation of the apical protrusion requires a bacterial aggregate, as protrusions are not observed underneath individual bacteria, but it remains unknown how formation of the aggregate is linked with changes to cell polarity (Tran et al. 2014a). Recent work suggests that aggregate formation requires the TTSS. Studies using a panel of isogenic TTSS mutants of $P$. aeruginosa showed that formation of the bacterial aggregate and subsequent polarity disruption required an intact TTSS needle complex, but did not require any of the known TTSS toxins. Indeed, addition of cell-free supernatants from MDCK cells infected with wild-type bacteria but not TTSS mutants was sufficient to induce bacterial aggregate formation on MDCK cells or on plastic surfaces. Together, these results suggest that membrane damage may be the inciting event (Tran et al. 2014b). However, other mechanisms, such as receptor clustering underneath aggregates, may still play a role. 


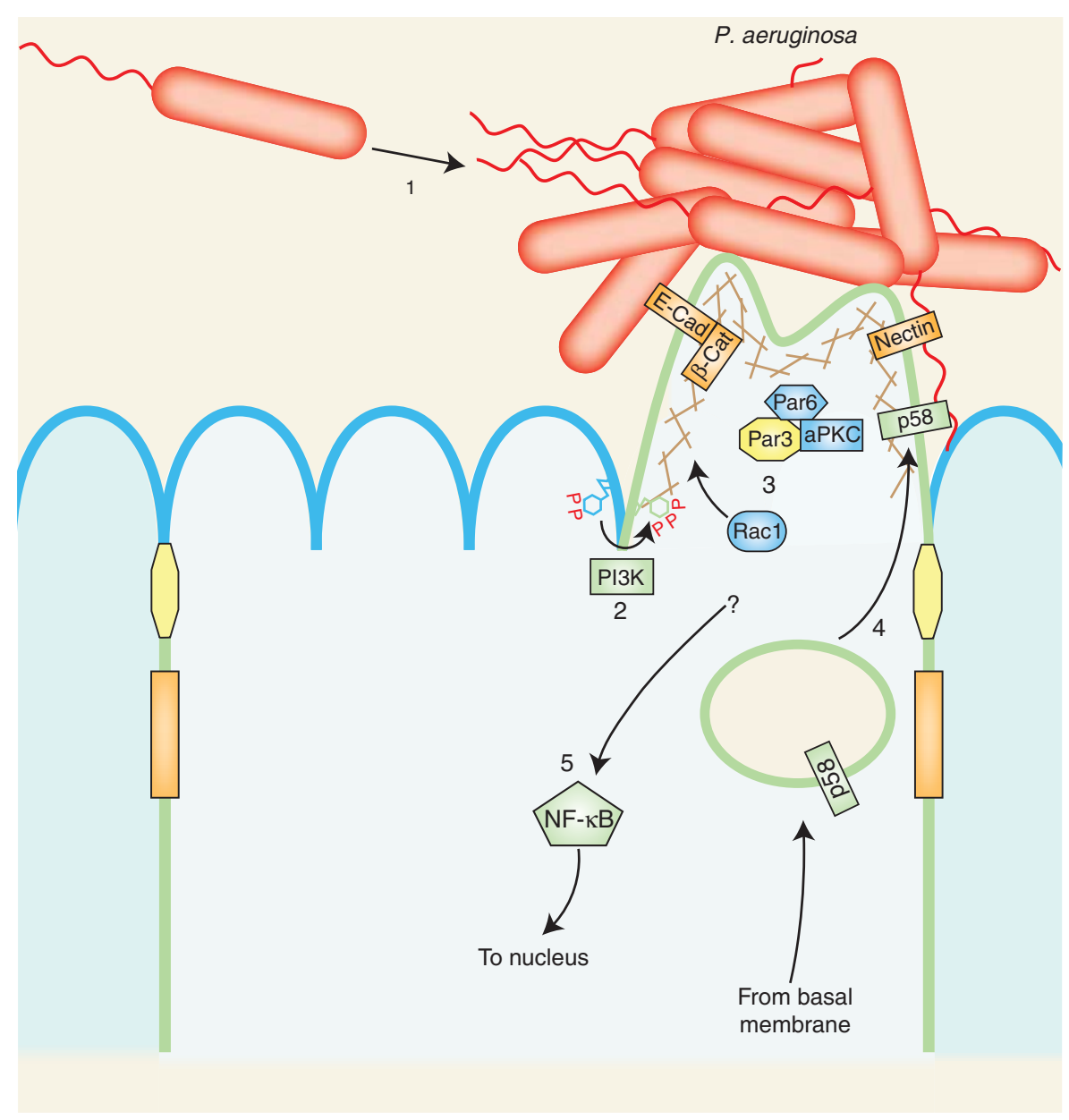

Figure 2. Pseudomonas aeruginosa aggregates drive apical membrane polarity inversion and NF- $\mathrm{KB}$ activation. (1) P. aeruginosa forms aggregates on the apical surface by recruiting free swimming bacteria. (2) Phosphatidylinositol 3-kinase (PI3K) is recruited to sites of aggregate formation where it facilitates apical accumulation of $\mathrm{PIP}_{3}$. (3) Racl recruitment drives actin rearrangement, and the partitioning defective (PAR) complex is recruited underneath the bacterial aggregate where it drives a change in apical polarity. (4) Polarity inversion involves the gain of basolateral markers via membrane trafficking and loss of apical markers without disruption of junctions. (5) NF- $\kappa \mathrm{B}$ is activated following polarity inversion through an undefined mechanism involving the PAR complex and the P. aeruginosa aggregate.

What is the purpose of protrusion formation and remodeling of the apical membrane? It may create a specialized replicative niche, and/or it may serve as a portal of entry for $P$. aeruginosa to be internalized into epithelial cells (Kierbel et al. 2005, 2007; Tran et al. 2014a; Wang et al. 2016). The latter event may lead to transcytosis (Hirakata et al. 2000), or it could represent a dead end for the endocytosed bac- teria, which are trafficked to the autophagolysosome and killed (Heimer et al. 2013). Indeed, the change in cell polarity underneath $P$. aeruginosa aggregates may explain its preference for binding at sites of cell damage or extrusion (Engel and Eran 2011). Since P. aeruginosa uses distinct mechanisms to bind the apical and basolateral domain, it is possible that recruiting basolateral proteins to the apical membrane al- 
lows more efficient colonization at the apical surface (Bucior et al. 2010, 2012).

Alternatively, protrusion formation may represent a host response. Indeed, $P$. aeruginosa aggregate formation and subsequent apical membrane remodeling is linked with activation of the innate immune response, as shown by localized nuclear translocation of NF-кB underneath aggregates but not beneath single bacteria. NF- $\kappa \mathrm{B}$ activation is dependent on the presence of Par3, suggesting that a link exists between cell polarity and innate immunity (Tran et al. 2014a). However, in subsequent studies "forcing" Par3 to the apical membrane using chemically induced dimerization, while sufficient to cause polarity inversion, was not sufficient to activate NF-кB (TR Ruch et al., in prep.). Thus, polarity alterations alone cannot drive innate immune activation on its own, and NF- $\kappa \mathrm{B}$ activation may require both alteration to polarity and the presence of a pathogen-associated molecular pattern (PAMP) such as flagellin or lipopolysaccharide.

In summary, the disruption of cell polarity may allow for $P$. aeruginosa to efficiently bind to the host cell, begin the early steps in biofilm formation, and shield the bacteria while it unleashes its virulence factors. This creates an interesting paradigm for the how mucosal pathogens must subvert the barrier. Modulation of host cell polarity may create a specialized niche for pathogens. However, host cells may monitor changes in apicobasolateral polarity as a danger signal that warns of an incoming threat. Thus, from the pathogen side, colonization must either be silent or rapidly toxic to bypass detection by the innate immune response.

\section{Helicobacter pylori}

H. pylori is human-adapted Gram-negative curved bacilli that is present in the gut of nearly $50 \%$ of the human population, with increasing frequency with age and with increasing prevalence, up to $97 \%$, in underdeveloped nations (Marshall and Warren 1984; Blaser 2006). The majority of those infected carry the bacteria asymptomatically for years; however, in up to $3 \%$ of the infected population $H$. pylori is associated with gastritis, peptic ulcer disease, metaplasia, atrophic gastritis, and malignancy, including gastric adenocarcinoma and lymphoma (Bennett et al. 2015). Indeed, $H$. pylori-associated malignancies are the only cancer that can be cured with antibiotics (Calvet et al. 2013). The spectrum and severity of disease results from a complex and finely tuned interplay between host susceptibility, environmental determinants, and $H$. pylori strain differences, which reflect coevolution between the pathogen and host for $>100,000$ years (Amieva and Peek 2016).

H. pylori infection begins in the stomach where the bacteria use a urease to neutralize and survive in the low $\mathrm{pH}$ environment (Krulwich et al. 2011). H. pylori then moves into the gastric mucosa via flagellar-based motility, where the mucus layer shields the bacteria from the low $\mathrm{pH}$ of the stomach. Approximately $20 \%$ of bacteria attach directly to gastric epithelial cells with a preference for binding at cellcell junctions, whereas the remainder remain within $25 \mu \mathrm{m}$ of the epithelial surface (Hessey et al. 1990; Amieva et al. 2003). More recent studies have suggested that in addition to binding to gastric epithelial cells, $H$. pylori also interacts selectively with stem or progenitor cells in the crypts (Amieva and Peek 2016). The major adhesins mediating $H$. pylori binding are blood-antigen binding protein $\mathrm{A}(B a b A)$ and sialic acid binding adhesin ( SadA) (Ilver et al. 1998; Mahdavi et al. 2002). The epithelial cell bound $H$. pylori locally changes cell polarity and trafficking to promote growth and establish a replicative niche using two secreted toxins: $\mathrm{cy}$ totoxin-associated gene $\mathrm{A}(\mathrm{Cag} A)$ and vacuolating toxin $\mathrm{A}(\operatorname{Vac} A)$. Much has been learned about these toxins by studying their effects on polarized cell lines, short-term ex vivo primary cell cultures, infected rodents, and, more recently, gastroids, three-dimensional cell cysts that model gastric glands (Barker et al. 2010).

VacA is a chromosomally encoded toxin that produces a $140-\mathrm{kD}$ precursor protein, which is cleaved to generate an $88-\mathrm{kD}$ protein that is secreted via the type $\mathrm{V}$ autotransporter secretion system (Cover and Blaser 1992; Telford et al. 1994). VacA forms a hexameric anion selective 
pore that can insert into host cell membranes and change cellular permeability (Czajkowsky et al. 1999; Szabo et al. 1999; Tombola et al. 1999). For example, in HeLa and MDCK cells, VacA intoxication leads to the disruption of polarized trafficking, including the delivery of lysosomal and basolateral cargo to the apical membrane (Satin et al. 1997; Tan et al. 2011). VacA can also drive the breakdown of tight junctions, leading to an increase in paracellular permeability (Papini et al. 1998). However, the exact mechanism that drives these changes is not fully understood.

$\operatorname{CagA}$ is a polymorphic, multidomain scaffolding protein with multiple copies of a tyrosine phosphorylated E-P-I-Y-A motif (Hatakeyama 2014). It is encoded in the Cag pathogenicity island, a horizontally acquired locus that encodes the type IV secretion system (T4SS) (Tegtmeyer et al. 2011). The tip components of the T4SS bind to the integrin $\alpha 5 \beta 1$ to trigger CagA delivery into the cytoplasm of gastric epithelial cells where it associates with the host cell plasma membrane (Odenbreit et al. 2000; Stein et al. 2000; Kwok et al. 2007; Tegtmeyer et al. 2011). Bacterial binding and/or CagA injection may preferentially occur at junctions, because integrins are localized to the basolateral membrane. Once translocated, CagA undergoes tyrosine phosphorylation, serves as a signaling hub to recruit a diverse array of host cell proteins, including key components that regulate cell polarity, and is linked to a multitude of changes at the cellular level. These effects include a dramatic change in cellular shape (originally termed "the hummingbird effect") along with an increase in cell motility, cellular proliferation, and modulation of host antimicrobial activities (Peek et al. 1997; Segal et al. 1999; Churin et al. 2001; Hatakeyama 2014). Microinjection of $H$. pylori into gastroids results in mislocalization of claudin-7, and increased proliferation, similar to what has been observed in H. pylori-infected gastric epithelial cells in vitro and in vivo (Wroblewski et al. 2015). Overexpression of CagA in MDCK cells recapitulates many of these phenotypes, including breakdown of junctions, loss of cell polarity, and induced cell migration (Bagnoli et al. 2005).
Once inside of host cells, CagA is phosphorylated on its E-P-I-Y-A motifs by members of the Src and Abl tyrosine kinase families (Asahi et al. 2000; Stein et al. 2002; Tammer et al. 2007). These events allow it to interact with the SH2 domains of a number of proteins and may correlate with its oncogenic potential (Ohnishi et al. 2008; Hatakeyama 2014). The tight junction proteins ZO-1 and JAM relocalize to sites of bound bacteria in a CagA-dependent manner (Noach et al. 1994; Amieva et al. 2003; Lai et al. 2006). CagA also interacts with E-cadherin and disrupts $\beta$-catenin signaling, leading to impaired cell-cell adhesion (Suzuki et al. 2005; Murata-Kamiya et al. 2007). Finally, CagA binds directly to and recruits the basolateral polarity determinant Par1b to the apical domain (Saadat et al. 2007; Zeaiter et al. 2008). Par1b localization is tightly regulated and is normally restricted from accessing the apical space by phosphorylation by aPKC $\zeta$, which forces Par1b to relocalize to the basolateral domain (Goehring 2014). CagA forms a complex with Par1b and aPKC $\zeta$ through binding to the substrate binding cleft of Par1. By serving as a substrate mimic for Par1b, CagA sterically blocks Par1b from accessing its normal targets, thereby inhibiting PAR1 kinase activity and disrupting both Parlb and aPKC $\zeta$ function (Saadat et al. 2007; Nesic et al. 2010). Disruption of Par1b function is likely the main mechanism by which $H$. pylori disrupts cell polarity, as expression of a dominant-negative Par1b phenocopies CagA expression, and overexpression of Par1b can inhibit the polarity changes elicited by CagA (Saadat et al. 2007; Zeaiter et al. 2008). As Par1 is required for the development and maintenance of tight junctions, inhibition of Par1 activity by CagA leads to the disruption of tight junctions, loss of epithelial apicobasolateral polarity, extrusion of cells from the surrounding polarized epithelial monolayer, initiation of multiple rounds of cell division, and epithelial-to-mesenchymal transition (EMT). However, CagA may use other mechanisms to disrupt mucosal barrier polarity. For example, CagA directly interacts and inhibits the function of protein kinase $\mathrm{C}$-related kinase 2 (PRK2), a protein that signals downstream of Rho GTPases and plays in role cell 
T.R. Ruch and J.N. Engel

polarity and cytoskeleton remodeling, in a gastric adenocarcinoma (AGS) cell line (Mishra et al. 2015). Thus, H. pylori mediates polarity disruption through secreted toxins that target key polarity proteins and disrupt their function (Fig. 3).

What are the consequences of $H$. pylorimediated disruption of epithelial cell polarity, and how does this relate to its ability to cause ulcer disease and malignancy? Disruption of cell polarity and cell-cell junctions may allow for bacteria in the lumen of the gut to access nutrients present on the basal side of the epithelium. However, $H$. pylori bound to polarized epithelial cells are able to replicate and survive in conditions, whereas free swimming bacteria are killed, suggesting that the apical membrane serves as a protective replicative niche (Tan et al. 2009). Loss of cell polarity may also reroute membrane traffic to acquire intracellular cargo. For example, in MDCK cells CagA- and VacAmediated polarity disruption drives the delivery

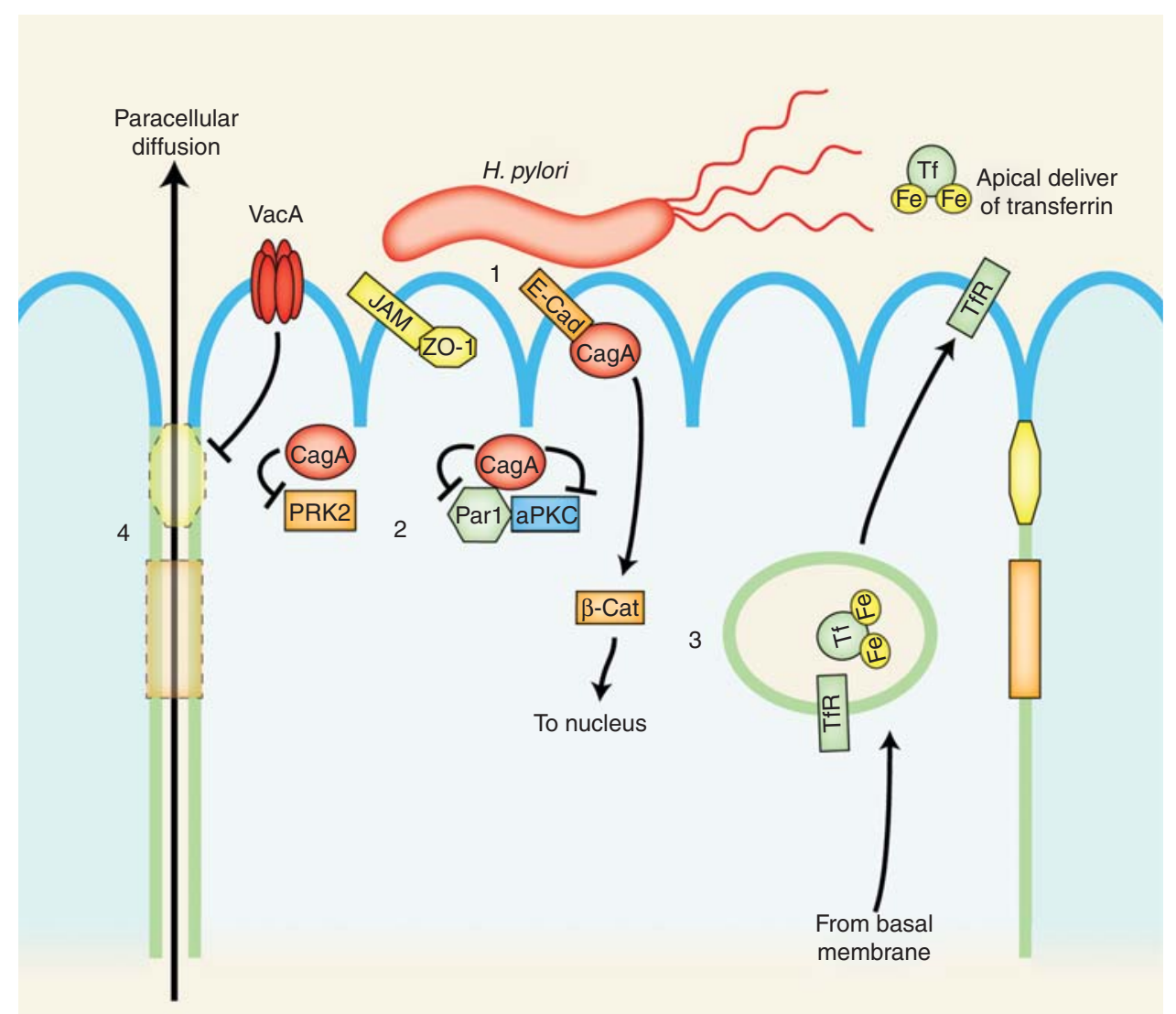

Figure 3. Helicobacter pylori alters cell polarity via the secreted bacterial toxins VacA and CagA. (1) H. pylori binding recruits components of tight junctions (ZO-1, junctional adhesion molecules [JAMs]) and adherens junctions (E-cadherin) to the apical membrane and activates $\beta$-catenin signaling. (2) CagA is translocated into the host cell via type IV secretion, where it directly interacts with the polarity proteins Parl and atypical protein kinase $\mathrm{C}(\mathrm{aPKC})$ and inhibits their kinase activity, leading to polarity disruption. CagA also independently interacts and inhibits the kinase activity of PRK2. (3) As a consequence of polarity disruption, basolateral cargo, such as the transferrin receptor (TfR), are delivered to the apical membrane via transcytosis, allowing $H$. pylori direct access to intracellular micronutrients. (4) Both CagA and VacA drive the breakdown of junctional complexes and weakening of junction function, which drives paracellular diffusion of macromolecules, such as sugars and iron, to move into the apical space. 
of intracellular fully saturated transferrin to H. pylori on the apical membrane (Tan et al. 2011). Acquisition of external iron is essential for growth of extracellular pathogens; thus, this mechanism allows $H$. pylori, which does not encode siderophores, to use host-derived transferrin as an iron source. Since partially saturated transferrin can be toxic to $H$. pylori, it seems that H. pylori uses epithelial cells as a filter to acquire micronutrients (Tan et al. 2011).

In cultured cells, ectopic expression of CagA can drive EMT that resembles the early stages of carcinogenesis, likely through targeting Parl (Stein et al. 2013). CagA-mediated dedifferentiation may lead to acquisition of cancer stemcell-like traits (Hatakeyama 2014). In vivo, however, these surface mucous cells turn over every few days, whereas evolution of $H$. pylori-induced cancer takes decades. It has been suggested that the ability of $H$. pylori to bind to and interact with gastric stem cells may also play an important role in gastric metaplasia and cancer (Amieva and Peek 2016).

\section{Neisseria meningitidis}

N. meningitidis is a Gram-negative diplococcus that is an obligate human pathogen. N. meningitidis colonizes the nasopharynx of $\sim 10 \%$ of the human population (Caugant and Maiden 2009). Spread occurs by nasal droplets or person to person spread. Individuals are typically colonized with a single clone, which clears within several months, and some clones are more invasive than others (Coureuil et al. 2014; Dwilow and Fanella 2015). In a very small percent of colonized individuals, $N$. meningitidis is able to cross the nasopharyngeal epithelial barrier and enter the bloodstream. Bacteremia can lead to sepsis (meninogoccemia), with severe vascular leakage and bacterial proliferation within the capillaries (purpura fulminans). In up to $50 \%$ of bacteremic individuals, blood-borne N. meningitidis is able to cross a specialized endothelial barrier, the blood-brain barrier, to infect the meninges and cause a severe and often fatal meningitis (Bernard et al. 2014). Below we discuss how $N$. meningitidis uses barrier-specific strategies that differ between epithelial and en-
Subversion of Cell Polarity by Mucosal Pathogens

dothelial surfaces, such as the nasopharyngeal epithelium and the blood-brain endothelial barrier.

During the course of infection, $N$. meningitidis encounters polarized epithelial and endothelial cells. In both settings, it initially attaches to the apical surface via direct binding of the bacterial type IV pili to the host receptor CD147 (Carbonnelle et al. 2006; Bernard et al. 2014). However, other bacterial surface proteins may play a role in attachment, including the opacity proteins Opa and Opc, the autotransporter NhhA, the adhesion protein App, and the trimeric autotransporter NadA (Virji 2000; Hadi et al. 2001; Comanducci et al. 2002; Serruto et al. 2003; Capecchi et al. 2005; Scarselli et al. 2006; Sjolinder et al. 2008). Once bound to apical surface, N. meningitidis replicates and forms microcolonies, which, similar to $P$. aeruginosa, elicit a dramatic change in the apical membrane of the underlying cell (Pron et al. 1997; Pujol et al. 1997). The host cell forms a honeycomb-shaped "cortical plaque" that surrounds the bacteria. These plaques are enriched in components of the actin cytoskeleton and provide a link between the bound bacteria and the actin network (Merz and So 1997; Merz et al. 1999).

The morphological changes, including cortical plaque formation at the apical membrane, are driven by several polarity signaling molecules. Initially, the host proteins ezrin and moesin, ERM proteins that cross-link actin filaments at the plasma membrane, localize around the bound bacteria leading to clustering and enrichment of receptors, such as CD44, ICAM$1,-2$, and E-selectin at the site of $N$. meningitidis binding (Merz et al. 1999). Subsequently, cortactin is recruited to and phosphorylated at the cortical plaque where it acts as a nucleation-promoting factor for the Arp $2 / 3$ complex and drives actin remodeling (Ammer and Weed 2008). In addition, the activity of Rho and Cdc42 are required for actin remodeling downstream of ezrin recruitment (Eugene et al. 2002). The formation of cortical plaques allows the bacteria to solidly anchor at the apical membrane and may allow acquisition of iron by recruiting the transferrin receptor to the cortical 
plaque (Fig. 4A) (Barrile et al. 2015). During asymptomatic colonization of the nasopharynx, this may be the extent of the interaction of N. meningitidis with polarized cells. However, as described in more detail below, it can also cross the barrier, enter the bloodstream, and access the endothelial barrier, leading to severe disease.

N. meningitidis uses a different mechanism to cross the endothelial and epithelial barrier. At the endothelial barrier, N. meningitidis disrupts junctional components and is able to efficiently cross the blood-brain barrier by movement of bacteria through a paracellular route (Fig. 4B). $N$. meningitidis binding to the human brain endothelial cell line hCMEC/D3 leads to the activation of the G-protein-coupled receptor (GPCR) $\beta 2$-andrenergic receptor ( $\beta 2 \mathrm{AR}$ ) independent of $G_{\alpha S}$, a process known as biased agonism (Coureuil et al. 2009, 2010). Following $\beta 2 \mathrm{AR}$ activation, there is recruitment of $\beta$-arrestins, which are molecular scaffolds that modulate GPCR function (Smith and Rajagopal 2016). The $\beta$-arrestins then recruit ezrin, radixin, and moesin (ERM) proteins and Src kinase, and cluster receptors to initiate signaling at cortical plaques (Coureuil et al. 2012). In addition, the growth factor receptor ErbB2 clusters underneath $N$. meningitidis aggregates where it activates Src kinase signaling (Hoffmann et al. 2001). Sustained GPCR activation and arrestin recruitment is accompanied by relocalization of the PAR signaling complex (Par3/Par6/ aPKC/Cdc42), along with components of tight junctions and adherins junctions, including p120-catenin, $\beta$-catenin, vascular endothelial (VE)-cadherin, ZO-1, ZO-2, and claudin-5, away from apical junctions to the site of $N$. meningitidis binding (Coureuil et al. 2009). Cortactin is recruited away from the nucleus and is phosphorylated by Src kinase, leading to actin reorganization, which stabilizes microcolony adhesion. By building what is essentially an ectopic junction, $N$. meningitidis disrupts cell polarity and weakens junctions by titrating away components necessary for their function. This process, combined with the fact that the tight junction protein occludin is cleaved, allows $N$. meningitidis to access the paracellular space and efficiently cross endothelial barriers (Schubert-Unkmeir et al. 2010).

In contrast, at the epithelial surface N. meningitidis is internalized through the binding of Opa to the CEACAM1 receptor (Griffiths et al. 2007). Formation of N. meningitidis microcolonies on a polarized human bronchial epithelial cell line (Calu3) did not result in activation of $\beta 2 A R$, recruitment of the PAR complex, or in breakdown of junctional structures (Lecuyer et al. 2012). Instead, N. meningitidis subsequently crossed the epithelial barrier by transcytosis in a taxol and nocodozole-sensitive manner, suggesting that a microtubule-dependent mechanism is required for either moving through the cell, or for efficient exit at the basolateral surface (Fig. 4A) (Sutherland et al. 2010). The mechanisms underlying these differences are incompletely understood. The $\beta 2 \mathrm{AR} / \mathrm{PAR}$ pathway is present in both epithelial and endothelial cells, but is only activated following binding at the endothelial surface. This may reflect variations in bacterial adhesins, host cell receptors, and/or endothelial versus epithelial specific tight junctional proteins, such as E-cadherin/ VE-cadherin or different claudin isoforms (Lecuyer et al. 2012).

The cortical plaques formed at endothelial cell surfaces differ in some respects from those formed at epithelial surfaces. At the endothelial surface, $N$. meningitidis induced cortical plaque formation allows the bacteria to resist shear flow in vitro, which may serve as a protective mechanism to prevent blood-flow-mediated dislodgement of bacteria in vivo at the endothelial surface (Mikaty et al. 2009). The large size of the microcolony on the endothelial cells may interfere with receptor-mediated endocytosis and prevent transcytosis across the endothelial barrier (Coureuil et al. 2014). In contrast, microcolony and cortical plaque formation at the epithelial surface does not resist shear stress, and the flatter microcolonies may be more susceptible to internalization (Lecuyer et al. 2012).

The related human-specific species Neisseria gonorrhoeae, is a primary pathogen of the genital tract and, even if asymptomatic, is almost always associated with disease at the tissue level and with inflammation (Bennett et al. 2015). Rarely, 


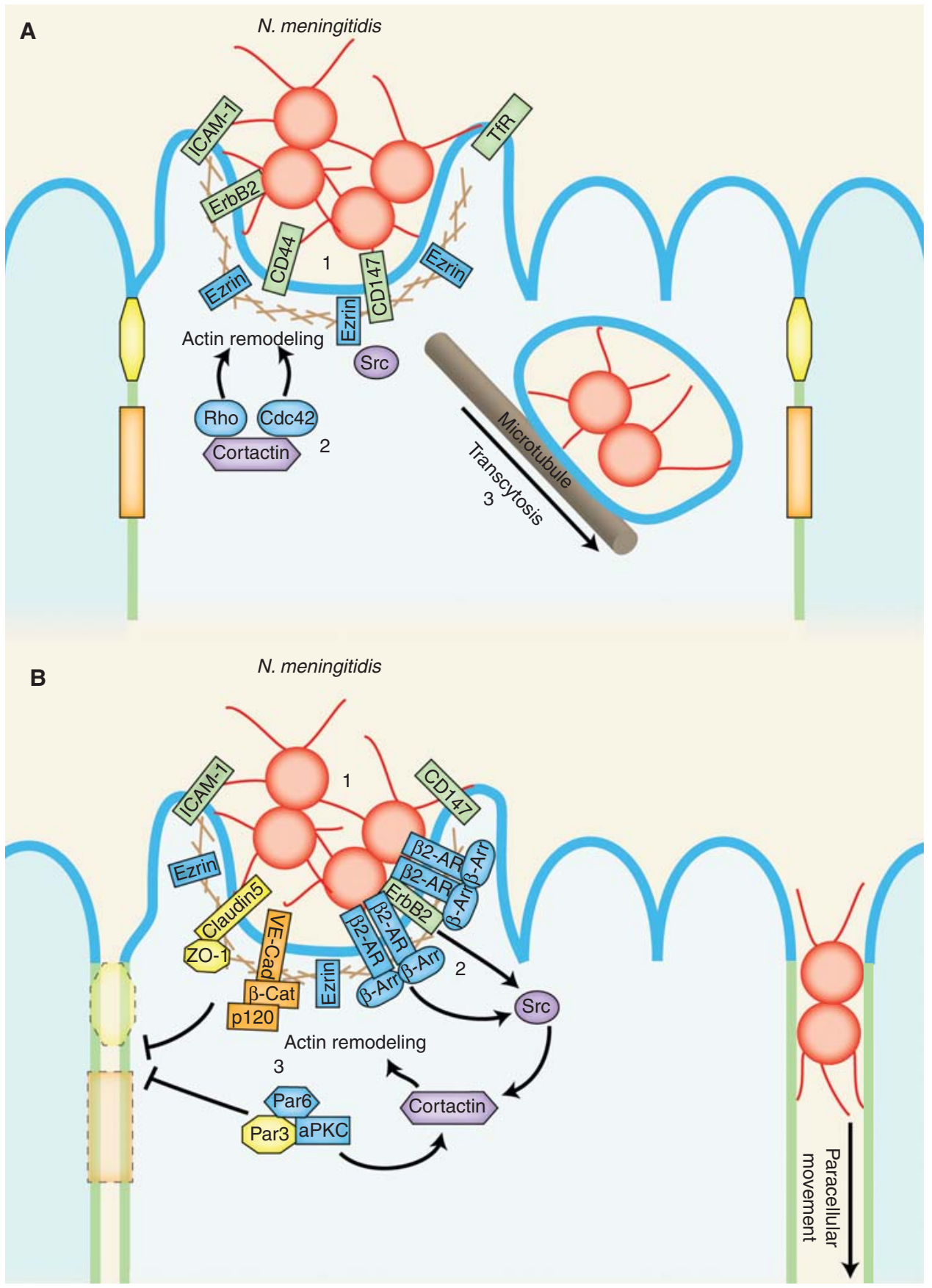

Figure 4. Neisseria meningitidis crosses polarized barriers using transcytosis (epithelial barrier) or paracellular movement (endothelial barrier). (A) Interaction of N. meningitidis with epithelial cells. (1) N. meningitidis type IV pilus-mediated binding to the apical surface leads to recruitment of ERM proteins and basolateral membrane proteins. (2) The actin network is remodeled to form a cortical plaque through the action of Rho, Cdc42, and cortactin. (3) N. meningitidis is internalized and transcytoses through cells in a microtubule-dependent manner. (B) Interaction of N. meningitidis with endothelial cells. (1) Binding of N. meningitidis leads to formation of a cortical plaque, similar to what occurs on epithelial cells. (2) N. meningitidis binds and activates $\beta 2 \mathrm{AR}$ leading to $\beta$-arrestin recruitment and Src activation. (3) Recruitment of the PAR complex and junctional proteins leads to the breakdown of cell-cell contacts and opens up the paracellular route. The PAR complex, along with Src, also recruits and activates cortactin. 
$N$. gonorrhoeae can cross the mucosal barrier into the bloodstream and disseminate to joints to cause infectious arthritis (Bennett et al. 2015). During initial colonization, both N. meningitidis and N. gonorrhoeae interface with the apical surface of polarized epithelial cells in their respective niches, the nasopharynx and the genital tract mucosa, respectively. However, N. gonorrhoeae is always associated with disease, whereas $N$. meningitidis is most commonly an asymptomatic colonizer of the nasopharynx. Interestingly, N. gonorrhoeae can also asymptomatically colonize the oropharynx, which serves as a reservoir for person-to-person spread, but little is known about host-pathogen interactions in this specific niche. Through the careful histological studies of diseased human tissue, the use of polarized epithelial and endothelial cell tissue culture models, a humanized mouse model in which human skin is engrafted onto severe combined immunodeficiency (SCID) mice and human brain sections (Bernard et al. 2014), we have learned that although N. meningitidis and N. gonorrhoeae use common strategies of microcolony formation, binding via type IV pili, and cortical plaque formation infection leads to very different outcomes. $N$. gonorrhoeae dissemination/bacteremia occurs $<3 \%$ individuals, and gonococcal meningitis, which would involve the bacteria crossing the blood-brain barrier, is extraordinarily rare
(Martin et al. 2008). Together, these observations highlight differences in the ability of $N$. meningitidis and N. gonorrhoeae to surmount the epithelial/endothelial barrier and suggests that the ability to subvert the polarity signaling network via hijacking of the PAR complex is important for crossing the blood-brain barrier.

\section{CONCLUDING REMARKS}

An emerging theme in microbial pathogenesis is the recognition that pathogens exploit or disrupt components of the mucosal barrier to facilitate colonization, to create a specialized niche for replication where they remain shielded from the host immune response, and/or to disseminate to distant tissues or to new hosts. This property is not unique to bacteria; several viruses, including adenovirus, $\alpha$-herpes viruses, reoviruses, coronaviruses, and hepatitis $\mathrm{C}$ target junctional complexes and polarity regulators (Bergelson 2009). Host cell polarity determinants are logical targets for pathogens, as control of epithelial cell polarity requires constant sensing of external cues. In addition, the signaling polarity signaling network may interface with the host innate immune response, although this connection has just begun to be explored.

In this review, we have summarized recent developments in our understanding of how

Table 1. Summary of interactions of Pseudomonas aeruginosa, Helicobacter pylori, and Neisseria meningitidis with polarized cells

\begin{tabular}{|c|c|c|c|}
\hline Events & $P$. aeruginosa & H. pylori & N. meningitidis \\
\hline $\begin{array}{l}\text { Polarized cells } \\
\text { encountered } \\
\text { during infection }\end{array}$ & Lung epithelia & Gastric epithelia & $\begin{array}{l}\text { Nasopharnyx epithelia, } \\
\text { microvascular epithelia }\end{array}$ \\
\hline Type of pathogen & Opportunistic, free living & $\begin{array}{l}\text { Commensal, obligate } \\
\text { human pathogen }\end{array}$ & $\begin{array}{l}\text { Commensal, obligate human } \\
\text { pathogen }\end{array}$ \\
\hline $\begin{array}{l}\text { Virulence factors } \\
\text { that target cell } \\
\text { polarity }\end{array}$ & $\begin{array}{l}\text { Flagella, type IV pillus, } \\
\text { TTSS, toxins }\end{array}$ & $\begin{array}{c}\text { Flagella, type IV secretion } \\
\text { system, Cag A, VacA }\end{array}$ & Type IV pillus \\
\hline $\begin{array}{l}\text { Polarity proteins } \\
\text { directly targeted }\end{array}$ & PAR complex & Par1, PRK2, cadherin & PAR complex \\
\hline Effect & $\begin{array}{l}\text { Polarity inversion (early), } \\
\text { activation of NF- } \mathrm{B} \text {, } \\
\text { barrier breakdown } \\
\text { (late) }\end{array}$ & $\begin{array}{l}\text { Leaky junctions, } \\
\text { acquisition of basal } \\
\text { and intracellular } \\
\text { micronutrients }\end{array}$ & $\begin{array}{l}\text { Leaky junctions, acquisition of } \\
\text { basal nutrients, transcytosis } \\
\text { (epithelial), paracellular } \\
\text { movement (endothelial) }\end{array}$ \\
\hline
\end{tabular}


three important human bacterial pathogens, P. aeruginosa, $H$. pylori, and N. meningitidis, that target polarity complex components to successfully colonize the apical surface of polarized barriers. Despite these commonalities, these bacteria colonize different niches within the human host and cause vastly different diseases (Table 1). Both P. aeruginosa and N. meningitidis use retractile type IV pili to bind to apical surfaces, where they form microcolonies and recruit the PAR complex, but the functional consequences are distinct. During $P$. aeruginosa infection, junctional components are not lost and the epithelial barrier remains intact at early stages. In contrast, N. meningitidis recruits junctional components to the site of microcolony binding, depleting and disrupting barrier function. From a disease point of view, the consequences are enormous. These cell biological processes may explain the why blood-borne $N$. meningitidis is able to cross the blood-brain barrier and cause meningitis, whereas $P$. aeruginosa, even during bacteremic episodes, is rarely reported to cause meningitis (Bennett et al. 2015). In contrast, H. pylori uses CagA and VacA to establish a very long-lived privileged niche. It disrupts polarity signaling partly through molecular mimicry, where CagA serves as a Par1B substrate mimic that disrupts Par1B/ aPKC signaling. In addition, CagA-mediated polarity disruption is associated with EMT and the development of cancer, showing that reprograming of the cellular polarity network cannot only disruption junctional function, but can lead to loss of cell identity.

\section{ACKNOWLEDGMENTS}

Funding support from the National Institutes of Health (NIH) RO1 065902, NIH Microbial Pathogenesis and Host Defense T32 Fellowship, and a Cystic Fibrosis Research Elizabeth Nash Memorial Fellowship are acknowledged.

\section{REFERENCES}

Amieva M, Peek RM Jr. 2016. Pathobiology of Helicobacter pylori-induced gastric cancer. Gastroenterology 150: 6478.
Amieva MR, Vogelmann R, Covacci A, Tompkins LS, Nelson WJ, Falkow S. 2003. Disruption of the epithelial apicaljunctional complex by Helicobacter pylori CagA. Science 300: $1430-1434$.

Ammer AG, Weed SA. 2008. Cortactin branches out: Roles in regulating protrusive actin dynamics. Cell Motil Cytoskeleton 65: 687-707.

Anderson JM, Van Itallie CM. 2009. Physiology and function of the tight junction. Cold Spring Harb Perspect Biol 1: a002584.

Apodaca G, Gallo LI, Bryant DM. 2012. Role of membrane traffic in the generation of epithelial cell asymmetry. Nat Cell Biol 14: 1235-1243.

Asahi M, Azuma T, Ito S, Ito Y, Suto H, Nagai Y, Tsubokawa M, Tohyama Y, Maeda S, Omata M, et al. 2000. Helicobacter pylori CagA protein can be tyrosine phosphorylated in gastric epithelial cells. J Exp Med 191: 593-602.

Assemat E, Bazellieres E, Pallesi-Pocachard E, Le Bivic A, Massey-Harroche D. 2008. Polarity complex proteins. Biochim Biophys Acta 1778: 614-630.

Bagnoli F, Buti L, Tompkins L, Covacci A, Amieva MR. 2005. Helicobacter pylori CagA induces a transition from polarized to invasive phenotypes in MDCK cells. Proc Natl Acad Sci 102: 16339-16344.

Barker N, Huch M, Kujala P, van de Wetering M, Snippert HJ, van Es JH, Sato T, Stange DE, Begthel H, van den Born M, et al. 2010. Lgr $5^{+ \text {ve }}$ stem cells drive self-renewal in the stomach and build long-lived gastric units in vitro. Cell Stem Cell 6: 25-36.

Barrile R, Kasendra M, Rossi-Paccani S, Merola M, Pizza M, Baldari C, Soriani M, Arico B. 2015. Neisseria meningitidis subverts the polarized organization and intracellular trafficking of host cells to cross the epithelial barrier. Cell Microbiol 17: 1365-1375.

Bennett JE, Dolin R, Blaser MJ. 2015. Mandell, Douglas, and Bennett's principles and practice of infectious diseases. Elsevier/Saunders, Philadelphia.

Benton R, St Johnston D. 2003. Drosophila PAR-1 and 14-33 inhibit Bazooka/PAR-3 to establish complementary cortical domains in polarized cells. Cell 115: 691-704.

Bergelson JM. 2009. Intercellular junctional proteins as receptors and barriers to virus infection and spread. Cell Host Microbe 5: 517-521.

Bernard SC, Simpson N, Join-Lambert O, Federici C, LaranChich MP, Maissa N, Bouzinba-Segard H, Morand PC, Chretien F, Taouji S, et al. 2014. Pathogenic Neisseria meningitidis utilizes CD147 for vascular colonization. Nat Med 20: 725-731.

Bhat MA, Izaddoost S, Lu Y, Cho KO, Choi KW, Bellen HJ. 1999. Discs Lost, a novel multi-PDZ domain protein, establishes and maintains epithelial polarity. Cell 96: 833-845.

Bilder D, Perrimon N. 2000. Localization of apical epithelial determinants by the basolateral PDZ protein Scribble. Nature 403: 676-680.

Bilder D, Li M, Perrimon N. 2000. Cooperative regulation of cell polarity and growth by Drosophila tumor suppressors. Science 289: 113-116.

Blaser MJ. 2006. Who are we? Indigenous microbes and the ecology of human diseases. EMBO Rep 7: 956-960. 
T.R. Ruch and J.N. Engel

Bryant DM, Datta A, Rodriguez-Fraticelli AE, Peranen J, Martin-Belmonte F, Mostov KE. 2010. A molecular network for de novo generation of the apical surface and lumen. Nat Cell Biol 12: 1035-1045.

Bucior I, Mostov K, Engel JN. 2010. Pseudomonas aeruginosa-mediated damage requires distinct receptors at the apical and basolateral surfaces of the polarized epithelium. Infect Immun 78: 939-953.

Bucior I, Pielage JF, Engel JN. 2012. Pseudomonas aeruginosa pili and flagella mediate distinct binding and signaling events at the apical and basolateral surface of airway epithelium. PLoS Pathog 8: e1002616.

Calvet X, Ramirez Lazaro MJ, Lehours P, Megraud F. 2013. Diagnosis and epidemiology of Helicobacter pylori infection. Helicobacter 18: 5-11.

Capaldo CT, Farkas AE, Nusrat A. 2014. Epithelial adhesive junctions. F1000Prime Rep 6: 1.

Capecchi B, Adu-Bobie J, Di Marcello F, Ciucchi L, Masignani V, Taddei A, Rappuoli R, Pizza M, Arico B. 2005. Neisseria meningitidis NadA is a new invasin which promotes bacterial adhesion to and penetration into human epithelial cells. Mol Microbiol 55: 687-698.

Carbonnelle E, Helaine S, Nassif X, Pelicic V. 2006. A systematic genetic analysis in Neisseria meningitidis defines the Pil proteins required for assembly, functionality, stabilization and export of type IV pili. Mol Microbiol 61: 15101522.

Caugant DA, Maiden MC. 2009. Meningococcal carriage and disease-Population biology and evolution. Vaccine 27: B64-B70.

Churin Y, Kardalinou E, Meyer TF, Naumann M. 2001. Pathogenicity island-dependent activation of Rho GTPases $\mathrm{Racl}$ and $\mathrm{Cdc} 42$ in Helicobacter pylori infection. Mol Microbiol 40: 815-823.

Comanducci M, Bambini S, Brunelli B, Adu-Bobie J, Arico B, Capecchi B, Giuliani MM, Masignani V, Santini L, Savino S, et al. 2002. NadA, a novel vaccine candidate of Neisseria meningitidis. J Exp Med 195: 1445-1454.

Coureuil M, Mikaty G, Miller F, Lecuyer H, Bernard C, Bourdoulous S, Dumenil G, Mege RM, Weksler BB, Romero IA, et al. 2009. Meningococcal type IV Pili recruit the polarity complex to cross the brain endothelium. Science 325: 83-87.

Coureuil M, Lecuyer H, Scott MG, Boularan C, Enslen H, Soyer M, Mikaty G, Bourdoulous S, Nassif X, Marullo S. 2010. Meningococcus Hijacks a $\beta 2$-adrenoceptor $/ \beta$-Arrestin pathway to cross brain microvasculature endothelium. Cell 143: 1149-1160.

Coureuil M, Join-Lambert O, Lecuyer H, Bourdoulous S, Marullo S, Nassif X. 2012. Mechanism of meningeal invasion by Neisseria meningitidis. Virulence 3: 164-172.

Coureuil M, Bourdoulous S, Marullo S, Nassif X. 2014. Invasive meningococcal disease: A disease of the endothelial cells. Trends Mol Med 20: 571-578.

Cover TL, Blaser MJ. 1992. Purification and characterization of the vacuolating toxin from Helicobacter pylori. J Biol Chem 267: 10570-10575.

Czajkowsky DM, Iwamoto H, Cover TL, Shao Z. 1999. The vacuolating toxin from Helicobacter pylori forms hexameric pores in lipid bilayers at low pH. Proc Natl Acad Sci 96: 2001-2006.
Dwilow R, Fanella S. 2015. Invasive meningococcal disease in the 21st century-An update for the clinician. Curr Neurol Neurosci Rep 15: 2.

Engel JN. 2003. Molecular pathogenesis of acute Pseudomonas aeruginosa infections. Severe infections caused by pseudomonas aeruginosa (ed. Hauser A, Rello J), pp. 201-230. Kluwer Academic/Plenum Press, New York.

Engel J, Eran Y. 2011. Subversion of mucosal barrier polarity by pseudomonas aeruginosa. Front Microbiol 2: 114.

Eugene E, Hoffmann I, Pujol C, Couraud PO, Bourdoulous S, Nassif X. 2002. Microvilli-like structures are associated with the internalization of virulent capsulated Neisseria meningitidis into vascular endothelial cells. J Cell Sci 115: 1231-1241.

Flores-Benitez D, Knust E. 2016. Dynamics of epithelial cell polarity in Drosophila: How to regulate the regulators? Curr Opin Cell Biol 42: 13-21.

Goehring NW. 2014. PAR polarity: From complexity to design principles. Exp Cell Res 328: 258-266.

Griffiths NJ, Bradley CJ, Heyderman RS, Virji M. 2007. IFN$\gamma$ amplifies NF-кB-dependent Neisseria meningitidis invasion of epithelial cells via specific upregulation of CEArelated cell adhesion molecule 1. Cell Microbiol 9: 29682983.

Hadi HA, Wooldridge KG, Robinson K, Ala'Aldeen DA. 2001. Identification and characterization of App: An immunogenic autotransporter protein of Neisseria meningitidis. Mol Microbiol 41: 611-623.

Hatakeyama M. 2014. Helicobacter pylori CagA and gastric cancer: A paradigm for hit-and-run carcinogenesis. Cell Host Microbe 15: 306-316.

Hauser AR. 2009. The type III secretion system of Pseudomonas aeruginosa: Infection by injection. Nat Rev Microbiol 7: 654-665.

Heimer SR, Evans DJ, Stern ME, Barbieri JT, Yahr T, Fleiszig SM. 2013. Pseudomonas aeruginosa utilizes the type III secreted toxin ExoS to avoid acidified compartments within epithelial cells. PloS ONE 8: e73111.

Hessey SJ, Spencer J, Wyatt JI, Sobala G, Rathbone BJ, Axon AT, Dixon MF. 1990. Bacterial adhesion and disease activity in Helicobacter associated chronic gastritis. Gut 31: 134-138.

Hirakata Y, Finlay BB, Simpson DA, Kohno S, Kamihira S, Speert DP. 2000. Penetration of clinical isolates of Pseudomonas aeruginosa through MDCK epithelial cell monolayers. J Infect Dis 181: 765-769.

Hoffmann I, Eugene E, Nassif X, Couraud PO, Bourdoulous S. 2001. Activation of ErbB2 receptor tyrosine kinase supports invasion of endothelial cells by Neisseria meningitidis. J Cell Biol 155: 133-143.

Ilver D, Arnqvist A, Ogren J, Frick IM, Kersulyte D, Incecik ET, Berg DE, Covacci A, Engstrand L, Boren T. 1998 Helicobacter pylori adhesin binding fucosylated histoblood group antigens revealed by retagging. Science 279: 373-377.

Kemphues KJ, Priess JR, Morton DG, Cheng NS. 1988. Identification of genes required for cytoplasmic localization in early C. elegans embryos. Cell 52: 311-320.

Kierbel A, Gassama-Diagne A, Mostov K, Engel JN. 2005. The phosphoinositol-3-kinase-protein kinase B/Akt 
pathway is critical for Pseudomonas aeruginosa strain PAK internalization. Mol Biol Cell 16: 2577-2585.

Kierbel A, Gassama-Diagne A, Rocha C, Radoshevich L, Olson J, Mostov K, Engel J. 2007. Pseudomonas aeruginosa exploits a PIP3-dependent pathway to transform apical into basolateral membrane. J Cell Biol 177: 21-27.

Krulwich TA, Sachs G, Padan E. 2011. Molecular aspects of bacterial pH sensing and homeostasis. Nat Rev Microbiol 9: $330-343$.

Kwok T, Zabler D, Urman S, Rohde M, Hartig R, Wessler S, Misselwitz R, Berger J, Sewald N, Konig W, et al. 2007. Helicobacter exploits integrin for type IV secretion and kinase activation. Nature 449: 862-866.

Lai YP, Yang JC, Lin TZ, Lin JT, Wang JT. 2006. Helicobacter pylori infection and CagA protein translocation in human primary gastric epithelial cell culture. Helicobacter 11: $451-459$.

Lecuyer H, Nassif X, Coureuil M. 2012. Two strikingly different signaling pathways are induced by meningococcal type IV pili on endothelial and epithelial cells. Infect Immun 80: 175-186.

Lepanto P, Bryant DM, Rossello J, Datta A, Mostov KE, Kierbel A. 2011. Pseudomonas aeruginosa interacts with epithelial cells rapidly forming aggregates that are internalized by a Lyn-dependent mechanism. Cell Microbiol 13: $1212-1222$.

Mahdavi J, Sonden B, Hurtig M, Olfat FO, Forsberg L, Roche N, Angstrom J, Larsson T, Teneberg S, Karlsson KA, et al. 2002. Helicobacter pylori SabA adhesin in persistent infection and chronic inflammation. Science 297: 573-578.

Marshall BJ, Warren JR. 1984. Unidentified curved bacilli in the stomach of patients with gastritis and peptic ulceration. Lancet 1: 1311-1315.

Martin MC, Perez F, Moreno A, Moral A, Alvarez MA, Mendez FJ, Vazquez F. 2008. Neisseria gonorrhoeae meningitis in pregnant adolescent. Emerg Infect Dis 14: 16721674.

Martin-Belmonte F, Mostov K. 2008. Regulation of cell polarity during epithelial morphogenesis. Curr Opin Cell Biol 20: 227-234.

McCaffrey LM, Macara IG. 2009. Widely conserved signaling pathways in the establishment of cell polarity. Cold Spring Harb Perspect Biol 1: a001370.

Merz AJ, So M. 1997. Attachment of piliated, Opa- and Opcgonococci and meningococci to epithelial cells elicits cortical actin rearrangements and clustering of tyrosinephosphorylated proteins. Infect Immun 65: 4341-4349.

Merz AJ, Enns CA, So M. 1999. Type IV pili of pathogenic Neisseriae elicit cortical plaque formation in epithelial cells. Mol Microbiol 32: 1316-1332.

Mikaty G, Soyer M, Mairey E, Henry N, Dyer D, Forest KT, Morand P, Guadagnini S, Prevost MC, Nassif X, et al. 2009. Extracellular bacterial pathogen induces host cell surface reorganization to resist shear stress. PLoS Pathog 5: e1000314.

Mishra JP, Cohen D, Zamperone A, Nesic D, Muesch A, Stein M. 2015. CagA of Helicobacter pylori interacts with and inhibits the serine-threonine kinase PRK2. Cell Microbiol 17: 1670-1682.
Morais-de-Sa E, Mirouse V, St Johnston D. 2010. aPKC phosphorylation of Bazooka defines the apical/lateral border in Drosophila epithelial cells. Cell 141: 509-523.

Murata-Kamiya N, Kurashima Y, Teishikata Y, Yamahashi Y, Saito Y, Higashi H, Aburatani H, Akiyama T, Peek RM Jr, Azuma T, et al. 2007. Helicobacter pylori CagA interacts with E-cadherin and deregulates the $\beta$-catenin signal that promotes intestinal transdifferentiation in gastric epithelial cells. Oncogene 26: 4617-4626.

Navarro C, Nola S, Audebert S, Santoni MJ, Arsanto JP, Ginestier C, Marchetto S, Jacquemier J, Isnardon D, Le Bivic A, et al. 2005. Junctional recruitment of mammalian Scribble relies on E-cadherin engagement. Oncogene 24: 4330-4339.

Nesic D, Miller MC, Quinkert ZT, Stein M, Chait BT, Stebbins CE. 2010. Helicobacter pylori CagA inhibits PAR1MARK family kinases by mimicking host substrates. Nat Struct Mol Biol 17: 130-132.

Noach LA, Rolf TM, Tytgat GN. 1994. Electron microscopic study of association between Helicobacter pylori and gastric and duodenal mucosa. J Clin Pathol 47: 699-704.

Odenbreit S, Puls J, Sedlmaier B, Gerland E, Fischer W, Haas R. 2000. Translocation of Helicobacter pylori CagA into gastric epithelial cells by type IV secretion. Science 287: 1497-1500.

Ogita H, Rikitake Y, Miyoshi J, Takai Y. 2010. Cell adhesion molecules nectins and associating proteins: Implications for physiology and pathology. Proc Jpn Acad Ser B Phys Biol Sci 86: 621-629.

Ohnishi N, Yuasa H, Tanaka S, Sawa H, Miura M, Matsui A, Higashi H, Musashi M, Iwabuchi K, Suzuki M, et al. 2008. Transgenic expression of Helicobacter pylori CagA induces gastrointestinal and hematopoietic neoplasms in mouse. Proc Natl Acad Sci 105: 1003-1008.

Papini E, Satin B, Norais N, de Bernard M, Telford JL, Rappuoli R, Montecucco C. 1998. Selective increase of the permeability of polarized epithelial cell monolayers by Helicobacter pylori vacuolating toxin. J Clin Invest 102: 813-820.

Peek RM Jr, Moss SF, Tham KT, Perez-Perez GI, Wang S, Miller GG, Atherton JC, Holt PR, Blaser MJ. 1997. Helicobacter pylori cag $\mathrm{A}^{+}$strains and dissociation of gastric epithelial cell proliferation from apoptosis. J Natl Cancer Inst 89: 863-868.

Pron B, Taha MK, Rambaud C, Fournet JC, Pattey N, Monnet JP, Musilek M, Beretti JL, Nassif X. 1997. Interaction of Neisseria meningitidis with the components of the blood-brain barrier correlates with an increased expression of PilC. J Infect Dis 176: 1285-1292.

Pujol C, Eugene E, de Saint Martin L, Nassif X. 1997. Interaction of Neisseria meningitidis with a polarized monolayer of epithelial cells. Infect Immun 65: 4836-4842.

Rodriguez-Boulan E, Macara IG. 2014. Organization and execution of the epithelial polarity programme. Nat Rev Mol Cell Biol 15: 225-242.

Roh MH, Makarova O, Liu CJ, Shin K, Lee S, Laurinec S, Goyal M, Wiggins R, Margolis B. 2002. The Maguk protein, Pals1, functions as an adapter, linking mammalian homologues of Crumbs and Discs Lost. J Cell Biol 157: 161-172.

Saadat I, Higashi H, Obuse C, Umeda M, Murata-Kamiya N, Saito Y, Lu H, Ohnishi N, Azuma T, Suzuki A, et al. 2007. 
Helicobacter pylori CagA targets PAR1/MARK kinase to disrupt epithelial cell polarity. Nature 447: 330-333.

Satin B, Norais N, Telford J, Rappuoli R, Murgia M, Montecucco C, Papini E. 1997. Effect of Helicobacter pylori vacuolating toxin on maturation and extracellular release of procathepsin $\mathrm{D}$ and on epidermal growth factor degradation. J Biol Chem 272: 25022-45028.

Scarselli M, Serruto D, Montanari P, Capecchi B, Adu-Bobie J, Veggi D, Rappuoli R, Pizza M, Arico B. 2006. Neisseria meningitidis NhhA is a multifunctional trimeric autotransporter adhesin. Mol Microbiol 61: 631-644.

Schubert-Unkmeir A, Konrad C, Slanina H, Czapek F, Hebling S, Frosch M. 2010. Neisseria meningitidis induces brain microvascular endothelial cell detachment from the matrix and cleavage of occludin: a role for MMP-8. PLoS Pathog 6: e1000874.

Segal ED, Cha J, Lo J, Falkow S, Tompkins LS. 1999. Altered states: Involvement of phosphorylated CagA in the induction of host cellular growth changes by Helicobacter pylori. Proc Natl Acad Sci 96: 14559-14564.

Serruto D, Adu-Bobie J, Scarselli M, Veggi D, Pizza M, Rappuoli R, Arico B. 2003. Neisseria meningitidis App, a new adhesin with autocatalytic serine protease activity. $\mathrm{Mol}$ Microbiol 48: 323-334.

Shen L, Weber CR, Raleigh DR, Yu D, Turner JR. 2011. Tight junction pore and leak pathways: A dynamic duo. Ann Rev Physiol 73: 283-309.

Shewan A, Eastburn DJ, Mostov K. 2011. Phosphoinositides in cell architecture. Cold Spring Harbor Perspect Biol 3: a004796.

Sjolinder H, Eriksson J, Maudsdotter L, Aro H, Jonsson AB. 2008. Meningococcal outer membrane protein NhhA is essential for colonization and disease by preventing phagocytosis and complement attack. Infect Immun 76: 5412-5420.

Smith JS, Rajagopal S. 2016. The $\beta$-arrestins: Multifunctional regulators of G-protein-coupled receptors. J Biol Chem 291: 8969-8977.

Soong G, Parker D, Magargee M, Prince AS. 2008. The type III toxins of Pseudomonas aeruginosa disrupt epithelial barrier function. J Bacteriol 190: 2814-2821.

Stein M, Rappuoli R, Covacci A. 2000. Tyrosine phosphorylation of the Helicobacter pylori CagA antigen after cagdriven host cell translocation. Proc Natl Acad Sci 97: 1263-1268.

Stein M, Bagnoli F, Halenbeck R, Rappuoli R, Fantl WJ, Covacci A. 2002. c-Src/Lyn kinases activate Helicobacter pylori CagA through tyrosine phosphorylation of the EPIYA motifs. Mol Microbiol 43: 971-980.

Stein M, Ruggiero P, Rappuoli R, Bagnoli F. 2013. Helicobacter pylori CagA: From pathogenic mechanisms to its use as an anti-cancer vaccine. Front Immunol 4: 328.

Su WH, Mruk DD, Wong EW, Lui WY, Cheng CY. 2012. Polarity protein complex Scribble/Lgl/Dlg and epithelial cell barriers. Adv Exp Med Biol 763: 149-170.

Sutherland TC, Quattroni P, Exley RM, Tang CM. 2010. Transcellular passage of Neisseria meningitidis across a polarized respiratory epithelium. Infect Immun 78: 3832-3847.

Suzuki M, Mimuro H, Suzuki T, Park M, Yamamoto T, Sasakawa C. 2005. Interaction of CagA with Crk plays an important role in Helicobacter pylori-induced loss of gastric epithelial cell adhesion. J Exp Med 202: 1235-1247.

Szabo I, Brutsche S, Tombola F, Moschioni M, Satin B, Telford JL, Rappuoli R, Montecucco C, Papini E, Zoratti M. 1999. Formation of anion-selective channels in the cell plasma membrane by the toxin VacA of Helicobacter pylori is required for its biological activity. $E M B O J \mathbf{1 8}$ : 5517-5527.

Tabuse Y, Izumi Y, Piano F, Kemphues KJ, Miwa J, Ohno S. 1998. Atypical protein kinase C cooperates with PAR-3 to establish embryonic polarity in Caenorhabditis elegans. Development 125: 3607-3614.

Tammer I, Brandt S, Hartig R, Konig W, Backert S. 2007. Activation of Abl by Helicobacter pylori: A novel kinase for CagA and crucial mediator of host cell scattering. Gastroenterology 132: 1309-1319.

Tan S, Tompkins LS, Amieva MR. 2009. Helicobacter pylori usurps cell polarity to turn the cell surface into a replicative niche. PLoS Pathog 5: e1000407.

Tan S, Noto JM, Romero-Gallo J, Peek RM Jr, Amieva MR. 2011. Helicobacter pylori perturbs iron trafficking in the epithelium to grow on the cell surface. PLoS Pathog 7: e1002050.

Tegtmeyer N, Wessler S, Backert S. 2011. Role of the cagpathogenicity island encoded type IV secretion system in Helicobacter pylori pathogenesis. FEBS J 278: 1190-1202.

Telford JL, Ghiara P, Dell'Orco M, Comanducci M, Burroni D, Bugnoli M, Tecce MF, Censini S, Covacci A, Xiang Z, et al. 1994. Gene structure of the Helicobacter pylori cytotoxin and evidence of its key role in gastric disease. J Exp Med 179: 1653-1658.

Tepass U, Knust E. 1993. Crumbs and stardust act in a genetic pathway that controls the organization of epithelia in Drosophila melanogaster. Dev Biol 159: 311-326.

Tepass U, Theres C, Knust E. 1990. Crumbs encodes an EGFlike protein expressed on apical membranes of Drosophila epithelial cells and required for organization of epithelia. Cell 61: 787-799.

Tombola F, Carlesso C, Szabo I, de Bernard M, Reyrat JM, Telford JL, Rappuoli R, Montecucco C, Papini E, Zoratti M. 1999. Helicobacter pylori vacuolating toxin forms anion-selective channels in planar lipid bilayers: Possible implications for the mechanism of cellular vacuolation. Biophys J 76: 1401-1409.

Tran CS, Eran Y, Ruch TR, Bryant DM, Datta A, Brakeman P, Kierbel A, Wittmann T, Metzger RJ, Mostov KE, et al. 2014a. Host cell polarity proteins participate in innate immunity to Pseudomonas aeruginosa infection. Cell Host Microbe 15: 636-643.

Tran CS, Rangel SM, Almblad H, Kierbel A, Givskov M, Tolker-Nielsen T, Hauser AR, Engel JN. 2014b. The Pseudomonas aeruginosa type III translocon is required for biofilm formation at the epithelial barrier. PLoS Pathog 10: e1004479.

Virji M. 2000. The structural basis of CEACAM-receptor targeting by neisserial opa proteins: Response. Trends Microbiol 8: 260-261.

Walther RF, Pichaud F. 2010. Crumbs/DaPKC-dependent apical exclusion of Bazooka promotes photoreceptor polarity remodeling. Curr Biol 20: 1065-1074. 
Subversion of Cell Polarity by Mucosal Pathogens

Wang Q, Margolis B. 2007. Apical junctional complexes and cell polarity. Kidney Int 72: 1448-1458.

Wang YC, Khan Z, Kaschube M, Wieschaus EF. 2012. Differential positioning of adherens junctions is associated with initiation of epithelial folding. Nature 484: 390393.

Wang C, de Jong E, Sjollema KA, Zuhorn IS. 2016. Entry of PIP3-containing polyplexes into MDCK epithelial cells by local apical-basal polarity reversal. Sci Rep 6: 21436 .

Wroblewski LE, Piazuelo MB, Chaturvedi R, Schumacher M, Aihara E, Feng R, Noto JM, Delgado A, Israel DA,
Zavros Y, et al. 2015. Helicobacter pylori targets cancerassociated apical-junctional constituents in gastroids and gastric epithelial cells. Gut 64: 720-730.

Zanin M, Baviskar P, Webster R, Webby R. 2016. The interaction between respiratory pathogens and mucus. Cell Host Microbe 19: 159-168.

Zeaiter Z, Cohen D, Musch A, Bagnoli F, Covacci A, Stein M. 2008. Analysis of detergent-resistant membranes of Helicobacter pylori infected gastric adenocarcinoma cells reveals a role for MARK2/Parlb in CagA-mediated disruption of cellular polarity. Cell Microbiol 10: 781-794. 


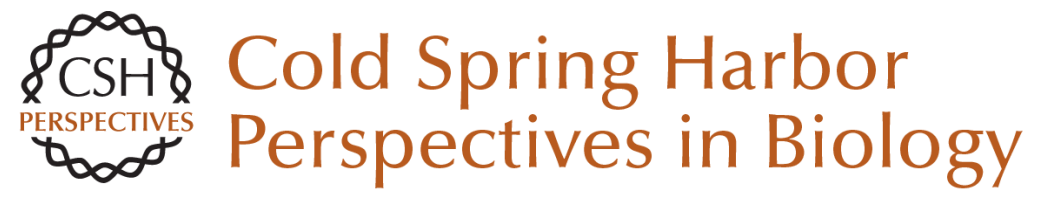

\section{Targeting the Mucosal Barrier: How Pathogens Modulate the Cellular Polarity Network}

Travis R. Ruch and Joanne N. Engel

Cold Spring Harb Perspect Biol 2017; doi: 10.1101/cshperspect.a027953 originally published online February 13, 2017

\section{Subject Collection Cell Polarity}

Regulation of Cell Polarity by Exocyst-Mediated

Trafficking Noemi Polgar and Ben Fogelgren

Phosphoinositides and Membrane Targeting in Cell Polarity

Gerald R. Hammond and Yang Hong

Trafficking lon Transporters to the Apical

Membrane of Polarized Intestinal Enterocytes Amy Christine Engevik and James R. Goldenring

Signaling Networks in Epithelial Tube Formation Ilenia Bernascone, Mariam Hachimi and Fernando Martin-Belmonte

Making Heads or Tails of It: Cell-Cell Adhesion in Cellular and Supracellular Polarity in Collective Migration Jan-Hendrik Venhuizen and Mirjam M. Zegers

Laminins in Epithelial Cell Polarization: Old

Questions in Search of New Answers

Karl S. Matlin, Satu-Marja Myllymäki and Aki Manninen

Epithelial Morphogenesis during Liver Development

Naoki Tanimizu and Toshihiro Mitaka
The Crumbs3 Polarity Protein

Ben Margolis

Microtubule Motors in Establishment of Epithelial Cell Polarity Geri Kreitzer and Monn Monn Myat

Role of Polarity Proteins in the Generation and

Organization of Apical Surface Protrusions Gerard Apodaca

Polarized Exocytosis Jingwen Zeng, Shanshan Feng, Bin Wu, et al.

Regulation of Transporters and Channels by Membrane-Trafficking Complexes in Epithelial Cells

Curtis T. Okamoto

Membrane Transport across Polarized Epithelia Maria Daniela Garcia-Castillo, Daniel J.-F. Chinnapen and Wayne I. Lencer

Mechanisms of Cell Polarity-Controlled Epithelial Homeostasis and Immunity in the Intestine Leon J. Klunder, Klaas Nico Faber, Gerard Dijkstra, et al.

For additional articles in this collection, see http://cshperspectives.cshlp.org/cgi/collection/

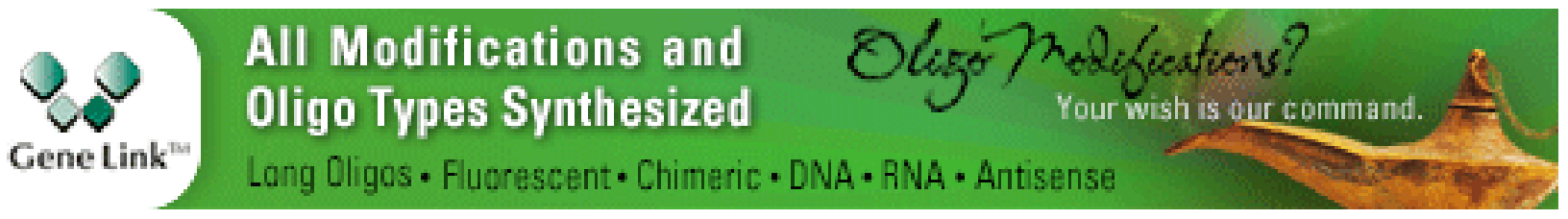


Targeting the Mucosal Barrier: How Pathogens Modulate the Cellular Polarity Network Travis R. Ruch and Joanne N. Engel

\section{The Biology of Ciliary Dynamics}

Kuo-Shun Hsu, Jen-Zen Chuang and Ching-Hwa Sung

For additional articles in this collection, see http://cshperspectives.cshlp.org/cgi/collection/

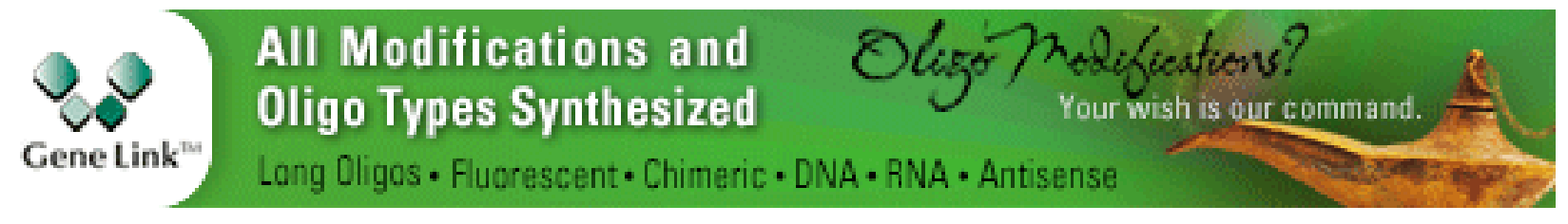

Copyright @ 2017 Cold Spring Harbor Laboratory Press; all rights reserved 